\title{
Mediated clustering and importation with implicit verbal chains
}

Phebe Cramer BARNARD COLLEGE

\begin{abstract}
Implicitly associated A-C pairs were separated, randomized, and presented for one trial learning. The significant A-C clustering which occurred in recall and the selective importation of the middle link of the chain (B) offer evidence for the existence of implicit associative chains.
\end{abstract}

\section{Introduetion}

By now, the importance of natural language associative bonds in determining the organization and errors of free recall has been amply demonstrated (e.g., Cofer, 1964). It has been shown, for example, that when pairs of words (A-B) are separated and presented for one trial learning, the probability of $A$ and $B$ being recalled together is a direct function of the strength of the associative bond between them (Jenkins et al, 1958).

An earlier study of the author (Cramer \& Holmes, 1961) investigated the possibility that implicit associative chains also might be influential in determining recall characteristics. Pairs of words $(A-C)$ were selected such that $A$ elicited $B$ as a response and $B$ elicited $C$ (but A did not elicit $C$ ); these pairs were separated, randomized, and presented for one trial learning. In this initial study, the results of free recall showed little evidence of (A-C) mediated clustering. However, when the "missing link" B words were interpolated between learning and recall, these B words were erroneously recalled as having been part of the learning list, while interpolated words which were not part of the associative chain were not imported into recall.

Thus, although the absence of $\mathrm{A}-\mathrm{C}$ clustering would suggest that there is not a chain from A through B to $\mathrm{C}$, we were hesitant to accept that conclusion considering the findings of previous mediated transfer studies (Russell \& Storms, 1955; McGehee \& Schulz, 1961), and considering the finding of $\mathrm{B}$ importation, which presumably was due to the associative relationship of the $\mathrm{B}$ words to both $\mathrm{A}$ and $\mathrm{C}$.

It is possible, however, to interpret the importation findings in a different fashion. It might be that the presentation of A alone is sufficient to cause the importation of $B$ into recall, in which case $B$ importation would not demonstrate the existence of an A-B-C chain. A second study was designed to investigate this possibility, as well as to separate out the effects of interpolated activity, of elapsed time, and of the nature of the interpolated task, both on importation and on $\mathrm{A}-\mathrm{C}$ clustering.

\section{Method}

All Ss were presented with one of three lists of words for one trial learning. One list (AC) consisted of the first and third members of the $12 \mathrm{~A}-\mathrm{B}-\mathrm{C}$ associative chains used in the previous experiment (for example, LONG-SHORT-TALL). The 12 A-C pairs were randomized, with the qualifications that (1) no A and $C$ word of any one pair occurred contiguously and (2) an equal number of $\mathrm{A}$ and $\mathrm{C}$ words was included in each half of the list. The chains were chosen to be non-overlapping; that is, there was a minimal $(<2 \%)$ associative connection among any of the $\mathrm{A}, \mathrm{B}$, and $\mathrm{C}$ words between chains, as determined from the Minnesota norms (Russell \& Jenkins, 1954). A second list (ACcon) consisted of the same A-C words, but the pairs were presented contiguously; for example, LONG was followed by TALL. For half of the pairs, the A word appeared first; for the other half, $C$ appeared first. A third list (AX) consisted of A-X "pairs." These X words were not associatively related to $\mathrm{A}$, but were systematically substituted for the $\mathrm{C}$ terms in order to form control pairs. Thus, if the fifteenth word on the randomized A-C list had been TALL (C), it was replaced by CHAIR (X), forming the A-X pair LONG-CHAIR. Three "filler" words were inserted at the beginning and at the end of each list.

Each of six groups of students from New York University (total $\mathrm{N}=131$ ) was instructed that they would be presented with a list of 30 words for one trial learning. It was stressed that order of recall was not important. The $\mathrm{E}$ read the words (and simultaneously presented them on $4 \times 6$ in printed cards) at the rate of 1 per sec. Following this, one group of Ss gave immediate recall; this group is designated AC-im, referring to a learning task of (randomized) A-C pairs, followed by immediate recall of the list.

For the other five groups, various tasks were interpolated between learning and recall. One group had a 2 min. blank interval, or delayed recall (AC-del). The interpolated task for three other groups was to circle "missing link" B words presented on a sheet of paper, as these were read aloud by $E$. The nature of the learning task differed for each of these three groups. One group learned randomized A-C pairs (AC-B), one group learned contiguous $A-C$ pairs (ACcon-B), and one group learned $\mathrm{A}-\mathrm{X}$ pairs $(\mathrm{AX}-\mathrm{B})$. The interpolated task for the last group was to circle nonassociatively related $\mathrm{X}$ words $(\mathrm{AC}-\mathrm{X})$. The overall 
retention interval (including instructions for interpolated task and recall) for these five groups was 2 min. All Ss were restricted to $4 \mathrm{~min}$. for recall of the original list.

\section{Results and Discussion}

Clustering. The groups differed significantly in number of associative clusters obtained ( $F=30.85$; $\mathrm{p}<.001$ ) (see Table 1). When the means are rank ordered and tested for significant differences, ACcon-B shows more clustering than AC-del and AC-B $(t=3.06$ and 3.10 , respectively; $\mathrm{p}<.005)$ and more than $\mathrm{AC}-\mathrm{im}$ and $\mathrm{AC}-\mathrm{X}(\mathrm{t}=4.71$ and 5.30 , respectively; $\mathrm{p}<.001)$. Furthermore, AC-del and AC-B show significantly more clustering than $\mathrm{AC}-\mathrm{X}(\mathrm{t}=2.32$ and 2.09, respectively; $\mathrm{p}<.05)$.

One might ask if the amount of clustering obtained was any greater than that which would be expected by chance. In this experiment, the chance level of associative clustering was determined by systematically substituting a control word (X) for each of the experimental words (C), and determining the number of A-X clusters which occur. According to this method, the expected mean is $.29(\mathrm{SD}=.48)$. When compared with this value, both the AC-del and AC-B groups show significant clustering $(t=2.28$ and 1.98; for a one-tailed test, $\mathrm{p}<.025$ and .05 , respectively). Group ACcon-B, of course, also shows significant clustering $(t=5.07$; $\mathrm{p}<.001$ )

Three general factors appear to have influenced associative clustering in this experiment. First, the passage of time alone resulted in an increase in clustering (AC-im vs. AC-del; $\mathrm{t}=1.95 ; \mathrm{p}<.06$ ). Second, the associative relationship of the interpolated task to the original list had a significant effect on clustering. Interpolation of a non-associative link (AC-X) resulted in significantly fewer A-C clusters, as opposed both to no interpolation (AC-del) and to interpolation

Table 1. Number of Associative Clusters and B Importations

$\begin{array}{lcccccc} & \begin{array}{r}\text { AC-B } \\ (\mathrm{N}=18)\end{array} & \begin{array}{c}\mathrm{AC}-\mathrm{X} \\ (\mathrm{N}=18)\end{array} & \begin{array}{c}\mathrm{AC}-\mathrm{im} \\ (\mathrm{N}=23)\end{array} & \begin{array}{c}\mathrm{AC}-\mathrm{del} \\ (\mathrm{N}=20)\end{array} & \begin{array}{c}\mathrm{AX}-\mathrm{B} \\ (\mathrm{N}=31)\end{array} & \begin{array}{r}\text { ACcon-B } \\ (\mathrm{N}=21)\end{array} \\ \begin{array}{l}\text { Clusters } \\ \text { Mean }\end{array} & .67 & .17 & .39 & .70 & - & 1.38 \\ \text { S. D. } & .68 & .37 & .57 & .64 & - & 1.00 \\ \begin{array}{l}\text { Importations } \\ \text { Mean }\end{array} & 1.28 & .05 & .09 & 0 & .32 & 1.14 \\ \text { S. D. } & 1.73 & .23 & .29 & - & .59 & .99\end{array}$

of an associatively related task (AC-B). Third, clustering was influenced by two aspects of the original learning task; both implicit associative relatedness between the A-C pairs (AC-B vs. AC-X) and contiguity in presentation (ACcon-B vs. AC-B) significantly increased clustering.

Importation. Table 1 also gives the data for importation. As in the previous experiment, the middle link (B) of the implicit verbal chains was imported into recall, but only where $\mathrm{B}$ had been presented in an interpolated task. Furthermore, in order for interpolated words to be imported, they must be associatively related to the words on the learning list (AC-C, AX-B, ACconB). Interpolated words which were not so related $(\mathrm{AC}-\mathrm{X})$ were not imported. Thus, when the number of $\mathrm{B}$ importations for Group $\mathrm{AC}-\mathrm{B}(\overline{\mathrm{X}}=1.28)$ was compared with the number of $\mathrm{X}$ importations for Group $\mathrm{AC}-\mathrm{X}$ $(X=.11)$, the results showed that $\mathrm{AC}-\mathrm{B}$ Ss clearly import more $B$ words than AC-X Ss import X words $(t=4.58$; $\mathrm{p}<.001)$.

An analysis of variance based on the three groups in which B importation did occur was significant at the .001 level $(\mathrm{F}=23.36)$. Individual $\mathrm{t}$ tests showed that $\mathrm{AC}-\mathrm{B}$ and ACcon-B imported significantly more $\mathrm{B}$ words than did $\mathrm{AX}-\mathrm{B}(\mathrm{t}=2.90$ and $2.57 ; \mathrm{p}<.01$ and .02 , respectively).

Thus, while importation does occur when only the first half of the associative chain (A) is present, it occurs significantly more often when both members of the chain (A and $\mathrm{C}$ ) are present. Both this finding and the significant clustering results offer further support for the existence of implicit associative chains.

\section{Referenees}

COFER, C. N. On some factors in the organizational characteristics of free recall. Tech. Rep. No. 1, Contract NONR 656(30), Penn. State Univer., 1964.

CRAMER, PHEBE, \& HOLMES, MONICA B. Clustering and importation in recall as a function of the interpolation of an associatively related task. Amer. Psychologist, 1961, 16, 466. (Abstract)

JENKINS, J. J., MINK, W. D。, \& RUSSELL, W. A. Associative clustering as a function of verbal association strength. Psychol. Rep., 1958, 4, 127-136.

McGEHEE, NAN E., \& SCHULZ, R. W. Mediation in verbal paired associate learning. J. exp. Psychol., 1961, 62, 565-570.

RUSSELL, W. A., \& JENKINS, J. J. The complete Minnesota norms for responses to 100 words from the Kent-Rosanoff Word Association Test. Tech. Rep. No. 11, Contract N8ONR-66216, University of Minnesota, 1954.

RUSSELL, W.A., \& STORMS, L.H.Implicit verbal chaining in pairedassociate learning. J. exp. Psychol., 1955, 49, 287-293. 